\title{
Representações sociais do alcoolismo construídas por não-alcoolistas
}

\author{
Social representations of alcoholism constructed by non-alcoholics \\ http://dx.doi.org/10.5007/2178-4582.2015v49n1p49
}

\author{
Luiz Gustavo Silva Souza \\ Universidade Federal Fluminense, Campos dos Goytacazes/RJ, Brasil \\ Maria Cristina Smith Menandro \\ e Zeidi Araújo Trindade \\ Universidade Federal do Espírito Santo, Vitória/ES, Brasil
}

\begin{abstract}
A compreensão das crenças sobre o alcoolismo pode ser importante para a implantação de políticas e práticas de saúde. Esta pesquisa investigou as representações sociais do alcoolismo construídas por não-alcoolistas brasileiros. Cinquenta adultos participaram deste estudo, 27 mulheres e 23 homens. Eles responderam a entrevistas semiestruturadas que abordaram crenças sobre o alcoolismo, atribuição causal, possíveis tratamentos e o alcoolista que não quer se tratar. Os dados foram analisados com análise de conteúdo temática. Os participantes representaram o alcoolismo como doença e vício, resultado de uma fraqueza inerente ao alcoolista, causado principalmente por problemas psicológicos. Sugeriram que a "força de vontade", os Alcoólicos Anônimos e a internação são as principais formas de tratamento. As representações do alcoolismo ancoraram em noções sobre moralidade e fracasso individual. A lógica da redução de danos parece não estar incorporada à cultura brasileira apesar de ser diretriz oficial para o cuidado em saúde.
\end{abstract}

Palavras-chave: Alcoolismo - Representações Sociais - Redução de danos.
Understanding the beliefs about alcoholism may be important for the implementation of health policies and practices. This research investigated the social representations of alcoholism constructed by Brazilian non-alcoholics. Fifty adults participated in this study, 27 women and 23 men. They responded to semi-structured interviews that addressed beliefs about alcoholism, causal attribution, possible treatments and alcoholics who do not want to be treated. Data were analyzed using thematic content analysis. Participants represented alcoholism as a disease and addiction, the result of the alchoholics' inherent weakness, mainly caused by psychological problems. They suggested that "will power", Alcoholics Anonymous and hospitalization are the main forms of treatment. The representations of alcoholism are anchored in notions as morality and individual failure. The logic of harm reduction seems not to be incorporated by Brazilian culture despite being official guideline for health care.

Keywords: Alcoholism - Social representations Harm reduction.

\section{Introdução}

Em diferentes sociedades e épocas, o consumo de álcool teve importantes significados religiosos, de partilha e celebração. Esses significados ainda estão vivos na atualidade e as sociedades industrializadas tratam o álcool de forma ambígua (HALPERN; LEITE, 2014; SOURNIA, 1986; SOUZA; NOTO, 
2013). A droga é associada ao convívio e ao prazer, mas também ao isolamento e à tragédia: acidentes de carro, violência intrafamiliar, problemas de saúde e grandes custos econômicos e sociais.

A noção de "alcoolismo" também é ambígua. Desde sua identificação como entidade nosológica, Alcoholismus Chronicus, por Magnus Huss, no século XIX, o alcoolismo foi considerado simultaneamente doença fisiológica e mental, bem como desvio moral individual. Há cerca de dois séculos, o alcoolismo entrou no domínio médico, em seus manuais e práticas (HALPERN; LEITE, 2014; SOURNIA, 1986).

Em meados do século XX, E. M. Jellinek disseminou o conceito de alcoolismo-doença, descrito como dependência de álcool, falta de controle sobre o consumo. Sua descrição da doença levou ao entendimento do alcoolismo como condição tudo-ou-nada. Mais tarde, o alcoolismo foi identificado como síndrome multifacetada e autores destacaram que uma gama mais ampla de padrões de consumo deveria ser abordada pela prática médica (SOURNIA, 1986; SOUZA; NOTO, 2013).

A pesquisa em ciências sociais contribuiu para a compreensão da variedade de significados da alcoolização. Trabalhos abordaram, por exemplo, as representações sociais do álcool e do alcoolismo em não-alcoolistas (ANCEL; GAUSSOT, 1998; ALVAREZ, 2001) e, em uma perspectiva mais ampla, a cultura do álcool na sociedade contemporânea (NAHOUM-GRAPPE, 2010).

Campos (2004) verificou que participantes dos Alcoólicos Anônimos representavam o alcoolismo como mal físico, associando-o à genética; como mal moral, associando-o à perda do controle e como "doença espiritual". Buscavam renomear o alcoolista como "doente em recuperação", de acordo com as imagens tradicionais do "homem correto", bom pai, bom marido, bom trabalhador. Em sua visão, o "alcoolismo ativo" impede que homens e mulheres assumam suas funções "naturais", respectivamente de provedor e chefe de família e de mãe e dona-de-casa. De forma semelhante, Alzuguir (2014) mostrou que alcoolistas constroem concepções sobre o alcoolismo que conjugam visões médicas e moralizantes, associando o sentimento de vergonha especialmente à recaída e à internação hospitalar.

Um estudo sobre as representações sociais do alcoolismo em não-alcoolistas brasileiros e cubanos sugeriu que o núcleo figurativo das representações é composto pelas ideias de vício, doença, problemas e conflitos. Os participantes afirmaram que a sociedade trata os alcoolistas com indiferença, desprezo, discriminação e exclusão (ALVAREZ, 2001).

Em um estudo francês, as representações sociais do alcoolismo não estiveram centradas na frequência e na quantidade do consumo, mas sim em 
ideias de perda de controle (do comportamento, da fala, da vontade) e de isolamento social (beber sozinho, ser incapaz de seguir protocolos sociais). As explicações científicas do alcoolismo (genética, fatores psicológicos e sociais) pareciam ser ambíguas e menos pregnantes que a imagem concreta da queda do alcoolista, de sua (auto)segregação e degeneração moral e social (ANCEL; GAUSSOT, 1998). Os autores enfatizam que a compreensão de representações sociais de não-alcoolistas sobre o alcoolismo pode revelar valores culturais e definições sobre o consumo "normal" de álcool.

Segundo levantamento recente, $6,8 \%$ dos brasileiros apresentam dependência do álcool. Esse índice é de 10,5\% entre homens e 3,6\% entre mulheres (LARANJEIRA et al., 2013). No Brasil, a lógica da redução de danos é apresentada como diretriz oficial para programas, serviços e práticas de atenção à saúde dirigidos a usuários de álcool e outras drogas (BRASIL, 2004).

Essa lógica é definida como uma estratégia de saúde pública que implica reduzir os danos ocasionados pelo abuso de substâncias psicoativas, "resgatando o usuário em seu papel autorregulador, sem a preconização imediata da abstinência e incentivando-o à mobilização social" (Ibid., p. 24). Sua sistematização ocorreu no início do século XX, na Inglaterra. A redução de danos se tornou um movimento internacional na década de 1980, em resposta à associação entre a AIDS e as drogas injetáveis. Ela preconiza que o usuário adote as melhores práticas de autocuidado mesmo que não deseje ou que não possa abster-se da droga que consome. Em perspectiva ampla, a redução de danos pode ser percebida como estratégia para promover cidadania e reverter a marginalização que afeta usuários de drogas (ANDRADE; FRIEDMAN, 2006; SANTOS; SOARES; CAMPOS, 2012)

Em que medida as ideias mencionadas até aqui estão presentes no senso comum? O objetivo da pesquisa relatada neste artigo foi compreender as representações sociais do alcoolismo construídas por brasileiros não-alcoolistas, em especial as causas e possíveis tratamentos associados ao fenômeno. A Teoria das Representações Sociais se mostra como referencial profícuo para análise dos conhecimentos de senso comum.

\section{Fundamentação teórica}

Representações sociais são fenômenos psicossociais. Sua construção é histórica e coletiva, mas, ao mesmo tempo, cada indivíduo as (re)constrói ativamente em sua experiência. São sistemas de conhecimentos, crenças e imagens que prescrevem valores para os objetos e comportamentos a eles dirigidos. Esses sistemas formam um mundo simbólico onde a vida humana acontece. O pensamento funciona como "ambiente" (MOSCOVICI, 1961/ 1978; 2007). 
A Teoria das Representações Sociais pressupõe que as sociedades estabelecem hierarquias de saber. O saber de senso comum é construído por meio da apropriação ativa e sincrética do saber "oficial" ou erudito, difundido pelos especialistas, pela mídia de massas e pelos vários outros atores de vulgarização da informação. Conhecimentos e crenças são apropriados e (re) construídos de forma diferente por cada grupo social, de acordo com seus interesses e injunções identitárias (JODELET, 1989/2005; MOSCOVICI, 2007).

A teoria prevê dois processos de formação das representações sociais: a objetivação e a ancoragem. A objetivação diz respeito à concretização de noções abstratas, ou seja, ao processo por meio do qual figuras tangíveis são selecionadas para dar inteligibilidade a certos conceitos, de forma que esses conceitos sejam facilmente visíveis na realidade. Esse processo inclui a seleção ativa de informações e imagens sobre o objeto e sua naturalização. A ancoragem, por sua vez, diz respeito à classificação do objeto em um conjunto pré-existente de conceitos, em sistemas de significados bem estabelecidos social e historicamente (TRINDADE; SANTOS; ALMEIDA, 2011).

\section{Método}

$\mathrm{O}$ estudo foi conduzido de acordo com as diretrizes de ética em pesquisa do Conselho Nacional de Saúde (Resolução CNS 466/12), aprovado por Comitê de Ética em Pesquisa de Universidade Federal. Os participantes assinaram Termo de Consentimento Livre e Esclarecido. Foram abordados 58 brasileiros adultos e nenhum se recusou a participar. Foi administrado um teste de triagem para problemas com o álcool, o CAGE (sigla que corresponde às primeiras letras de expressões que compõem, na versão em inglês, as quatro perguntas do teste: Cut down, Annoyed, Guilty e Eye-opener), de forma a incluir apenas aqueles que não tivessem indicação de problemas com o álcool. O CAGE é composto por quatro questões de sim ou não. Foi utilizado o ponto de corte tradicional do teste: a resposta positiva a duas questões (SANTOS et al, 2013). Foram excluídos da análise os participantes que responderam "sim" a duas ou mais questões (oito participantes foram excluídos por esse motivo). Retiveram-se, portanto, 50 participantes considerados não-alcoolistas, 27 mulheres e 23 homens, com idades entre 18 e 57 anos, com média de 31,66 anos de idade $(D P=10,17)$.

Quanto à condição socioeconômica, contou-se com 25 participantes de classe média (renda familiar mensal $>4$ salários mínimos) e 25 participantes de classe popular (renda familiar mensal $<4$ salários mínimos); o conjunto de participantes ficou assim balanceado, mas não houve pretensão de com- 
paração entre os dois grupos. Os participantes de classe média tinham ensino superior completo ou incompleto. Os de classe popular apresentaram o ensino médio completo e o ensino fundamental completo ou incompleto como níveis de escolaridade mais frequentes.

\section{Instrumento e procedimentos}

Os participantes foram escolhidos por conveniência e abordados em seus locais de trabalho. Foram aplicadas entrevistas semiestruturadas de forma individual, sempre em ambiente reservado. As entrevistas foram baseadas em um roteiro composto por cinco questões: 1) O que você sabe sobre o alcoolismo?; 2) Como se explica o alcoolismo?; 3) Acha que tem tratamento? Como tem que ser esse tratamento?; 4) O que você diria de um "alcoólatra" que não quer se tratar?; e 5) Algo deve ser feito a um "alcoólatra" que não quer se tratar? Se sim, o quê?

No roteiro semiestruturado, preferiu-se o termo "alcoólatra" por ser de uso mais corrente no senso comum. Todas as cinco questões foram feitas a todos os participantes, mas, seguindo o caráter semiestruturado, o pesquisador fez novas questões e comentários a cada entrevista, para fomentar a expressão e explorar aspectos interessantes das repostas.

As entrevistas foram gravadas em áudio e transcritas literalmente. Em seguida, foram submetidas à análise de conteúdo temática, com os procedimentos de leitura flutuante, identificação dos núcleos de sentido e interpretação dos temas. As implicações lógicas de diferentes respostas fornecidas pelos participantes foram exploradas. Categorias analíticas foram construídas de forma indutiva, por meio do procedimento de comparação constante (BARDIN, 1977; POPE; ZIEBLAND; MAYS, 2005).

\section{Resultados}

São expostas, a seguir, tabelas nomeadas como questões e os temas citados pelos participantes aparecem como respostas. Cada participante pode ter citado mais de um tema simultaneamente e as porcentagens exibidas foram calculadas com base no número total de entrevistas. Assim, as porcentagens descrevem a frequência e, por inferência, a "força" do tema no discurso do grupo estudado.

Como se vê na Tabela 1, a seguir, a maior parte dos participantes definiu o alcoolismo como doença, como vício, ou como os dois simultaneamente. Isso abre a questão sobre como conceituavam doença e vício. $\mathrm{O}$ vício foi definido como: hábito difícil de eliminar; algo que precisa ser feito com 
frequência,; atividade priorizada sobre as demais; e condição para outras atividades. E por que o alcoolismo pode ser visto como uma doença? Os participantes responderam principalmente: porque o "alcoólatra" não consegue se controlar. Outras explicações foram: porque precisa de tratamento; porque causa doenças físicas e/ou leva à morte; porque pode ser genético; e porque tira capacidade física e mental de agir. Destacam-se palavras associadas à doença: tratamento, morte, genética, incapacidade. Mas, a falta de controle é o elemento que parece caracterizar especificamente a doença alcoólica.

Tabela 1: O que é o alcoolismo?

\begin{tabular}{lcc}
\hline Temas & n & \% \\
\hline É uma doença & 25 & $50 \%$ \\
É um vício & 22 & $44 \%$ \\
É beber sem controle & 6 & $12 \%$ \\
É uma dependência química & 3 & $6 \%$ \\
É um mal & 2 & $4 \%$ \\
É um problema psicológico & 1 & $2 \%$ \\
É um transtorno & 1 & $2 \%$ \\
\hline
\end{tabular}

Os participantes que declararam que o alcoolismo é uma doença não tinham dificuldade em dizer que também é um vício (algumas pessoas citaram, de fato, os dois termos nessa ordem). Entretanto, o contrário não foi necessariamente verdadeiro: algumas pessoas afirmaram que o alcoolismo é um vício e negaram expressamente que pudesse ser uma doença. Adicionalmente, em algumas entrevistas, diante da dificuldade de explicar por que o alcoolismo é uma doença, algumas pessoas "recuaram" e o redefiniram como vício. A preponderância dessa descrição apareceu também quando alguns participantes tentaram diferenciar vício e doença, como no caso abaixo:

Participante: [...] vício e doença... Vício ele é acarretado porque a pessoa bebe constantemente, aí, uma vez ou outra, ela começa a beber constantemente, aí torna-se um vício. Agora, doença, tem uma semelhançazinha, porque começa também aí, daí a pouco, se enraíza no corpo da pessoa, aumenta.

Pesquisador: Então seria um vício mesmo?

Participante: Isso. 
A participante associou o vício ao beber constante e a doença a algo que "se enraíza no corpo da pessoa". Vício e doença seriam faces da mesma moeda: o vício é o comportamento de um corpo que é doente porque tem um vício que "se enraizou".

Na Tabela 1, "É um mal” é o único tema realmente discrepante: nas duas vezes em que foi citado, denotou uma apreensão religiosa do alcoolismo, que seria causado por influências malignas sobrenaturais.

Tabela 2: Quais são as causas do alcoolismo?

\begin{tabular}{lcc}
\hline Temas & $\mathbf{n}$ & $\mathbf{\%}$ \\
\hline Problemas emocionais e/ou interpessoais & 27 & $54 \%$ \\
A busca por uma fuga dos problemas & 20 & $40 \%$ \\
A pessoa cria um hábito & 12 & $24 \%$ \\
Influência de amigos & 11 & $22 \%$ \\
A pessoa é fraca & 5 & $10 \%$ \\
Genética & 5 & $10 \%$ \\
Falta de controle dos pais & 2 & $4 \%$ \\
Prazer da bebida, diversão & 2 & $4 \%$ \\
Influência maligna & 1 & $2 \%$ \\
Uma opção pessoal & 1 & $2 \%$ \\
Influência de pais que bebem & 1 & $2 \%$ \\
\hline
\end{tabular}

Na Tabela 2 o tema da influência maligna (sobrenatural) foi pouco citado. Também foram temas pouco citados como causa do alcoolismo: a influência de pais que bebem, uma opção pessoal, o prazer da bebida e a falta de controle de pais. A herança genética foi citada em apenas um décimo das entrevistas. Os temas mais frequentes foram os dois primeiros. A maior parte dos participantes acreditava que o alcoolismo é causado por problemas de ordem emocional ou interpessoal, e/ou que ele é causado por uma busca de fuga dos problemas. Seguem alguns exemplos relacionados ao primeiro desses temas:

[...]às vezes pode ser assim algo que aconteceu na família muito forte.

[...] sem afeto, sem um carinho, de algum pai, ou parente, ou irmão. Se torna um ser solitário, né, e acaba arrumando um 
próprio parceiro, né, uma companhia pra ele, pra se tornar um viciado, né, um alcoólico.

O pai dele fez tudo pela irmã, deu casa, deu móvel, né, fez o casamento, e ele sempre foi o 'patinho feio', né, mais desprezado. Aí, isso aí causou uma rejeição nele, se envolveu com má companhia e pegou o vício da bebida.

[...] porque eu acho que ela [a doença] é fruto de processos mal resolvidos internamente. Problemas com autoestima, [...] medos, ambições.

[...] acho que é uma questão de atitude. O que eu observo, assim, de quem bebe muito assim que não tem o controle, eu penso que tudo começa com um problema da pessoa, assim, um problema na cabeça.

Nessas falas, o alcoolismo aparece como efeito de problemas que adquirem valor traumático: a solidão, a rejeição, os medos, etc. Os participantes citaram mais frequentemente problemas familiares, e/ou no trabalho e também citaram problemas amorosos e financeiros. $\mathrm{O}$ último trecho menciona "um problema na cabeça": o alcoolismo seria fruto de algum mal funcionamento psicológico. A palavra "trauma" aparece literalmente em uma das entrevistas: "a maioria dessas pessoas que bebem é porque se afastam da família, se afastam da igreja, porque é... se veem sozinhas, perdidas, ou por algum trauma que sofre."

Algumas vezes, o alcoolismo foi descrito como epifenômeno de um problema psicológico de base, como no exemplo: "Às vezes a doença nem é o alcoolismo. O alcoolismo foi uma doença que ela [a pessoa] conseguiu devido a problemas, problemas pessoais que a pessoa tem". Os participantes utilizaram também o argumento da fuga: a pessoa se torna "alcoólatra" porque busca fugir dos problemas, esconder-se de uma realidade que ela não suporta:

Às vezes, a pessoa não sabe lidar com as frustrações do mundo e assume um vício para poder fugir da realidade.

Eu imagino que seja uma fuga.

Não tá bem com sua realidade. Bebe para levar a vida adiante.

Acha que a solução de seus problemas é através da bebida que soluciona.

No grupo estudado, o alcoolismo era visto, portanto, como resultado de problemas emocionais e/ ou interpessoais: ora os problemas apareciam como trauma, cujo efeito é a doença, e ora como desafio insuportável do qual o 
"alcoólatra" quer fugir. Pode-se inferir que esses dois temas estejam entrelaçados. Alguns participantes fizeram, eles mesmos, a junção desses argumentos, como no exemplo:

Participante: eu acho que ele foi por uma perda que ele teve, de uma pessoa, da esposa dele, né, que ele não conseguiu superar. Ele se separou.

Pesquisador: Então, assim, é uma tristeza que leva a pessoa a ser alcoólatra?"

Participante: É, isso, pode ser. Não conseguem enfrentar o problema.

Isso leva à exposição de um tema ainda não tratado, que se apresenta como parte importante das crenças sobre o fenômeno: "a pessoa é fraca". Esse tema apareceu diretamente poucas vezes (10\%). Entretanto, pode-se inferir que ele está implícito nos dois temas mais citados. Nem todas as pessoas que têm problemas emocionais, familiares, no trabalho, etc., se tornarão "alcoólatras". Isso só se dá com pessoas que são "fracas" e que (por acaso ou não) se encontram com a bebida, por "criar um hábito" ou por "influência de amigos". Só uma "pessoa fraca" sucumbe a um trauma e/ou quer fugir dos problemas e da realidade. $\mathrm{O}$ argumento de fraqueza fica explícito nas citações abaixo:

A pessoa se deixar levar pela bebida. Deixar levar. Aí, se ela não tiver força de vontade de sair daquilo, ela cai mesmo.

São pessoas fracas, né, que acabam consumindo alguma coisa e não conseguem parar.

Acho que é a pessoa que tem a mente fraca. Ele quer parar, mas os colegas incentivam ele e ele vai bebendo, bebendo e não consegue mais controlar.

A bebida aparece como uma entidade ativa: ela é que "leva"; e o "alcoólatra", por oposição, é passivo, ele é o "fraco" que não soube resistir à força intrínseca da bebida.

Tabela 3: Como deve ser o tratamento do alcoolismo?

\begin{tabular}{llc}
\hline Temas & $\mathrm{n}$ & $\%$ \\
\hline Tem que ter força de vontade & 26 & $52 \%$ \\
Alcoólicos Anônimos & 24 & $48 \%$ \\
Tratamento com internação (em clínica/ casa de recuperação) & 19 & $38 \%$
\end{tabular}


Com profissionais (médico, psicólogo, terapeuta, assistente social) $\quad 18 \quad 36 \%$

A família tem que apoiar e/ou também tem que ser tratada $\quad 16 \quad 32 \%$

$\begin{array}{lll}\text { Seguir uma religião } & 7 \quad 14 \%\end{array}$

Em clínica especializada (sem citar internação) $\quad 4 \quad 8 \%$

$\begin{array}{lll}\text { Com medicação } & 4 \quad 8 \%\end{array}$

Controle por parte da família $\quad 2 \quad 4 \%$

Criar vínculo de amizade com o "alcoólatra" primeiro $1 \quad 2 \%$

Afastar-se dos amigos que bebem $1 \quad 2 \%$

Não adianta internar $1 \quad 2 \%$

A Tabela 3 traz a questão sobre como deve ser o tratamento do alcoolismo. A resposta mais frequente foi uma decorrência lógica das causas expostas acima. Se o problema é fraqueza, o antídoto é a força ("força de vontade"). Perguntou-se aos participantes "você acha que o alcoolismo tem tratamento?". Todos responderam que sim e a resposta muitas vezes veio acompanhada do argumento "mas, a pessoa tem que querer", "tem que ter força de vontade".

Como alternativas de tratamento, os participantes falaram mais dos Alcoólicos Anônimos, da internação e da ajuda de profissionais (médico, psicólogo, terapeuta e assistente social). Também foi frequente a ideia de que a família do "alcoólatra" tem que apoiar e/ou também tem que ser tratada. Percebe-se a pregnância social dos Alcoólicos Anônimos (AA). Alguns participantes descreveram adequadamente esse grupo de mútua ajuda. Outros disseram não saber como o AA funciona. Em quatro ocasiões, surgiram descrições francamente equivocadas do AA, como as que se seguem:

Pessoas com o mesmo problema, buscam as causas do alcoolismo. Tem profissionais que atendem (psicólogos, terapeutas) e voluntários.

Lá tem psicólogos, tem acompanhamento, eu acredito (que eu nunca fui nem visitei). Mas, o que você ouve falar, diz que muitas pessoas se livraram, né, [do alcoolismo] e se livram até hoje. Você encaminha... Isso também tem que ter vontade, tem que querer. Porque se a pessoa não quiser, você internar lá à força pode até funcionar, mas não tem muito êxito não. Eu acho.

É interessante verificar que nenhum dos participantes citou, como alternativa de tratamento, o CAPS-ad (Centro de Atenção Psicossocial - álcool e drogas), que é uma instituição-chave para o tratamento de problemas re- 
lacionados a álcool e outras drogas segundo a política de saúde brasileira (BRASIL, 2004), mesmo havendo um CAPS-ad no município pesquisado. Também não houve qualquer referência à lógica de redução de danos.

Tabela 4: O que pensar de um "alcoólatra" que não quer se tratar?

\begin{tabular}{lcc}
\hline Temas & $\mathrm{n}$ & $\%$ \\
\hline Não tem amor próprio, à vida & 16 & $32 \%$ \\
É covarde, não quer mudança & 7 & $14 \%$ \\
Só vai se convencer quando sofrer o suficiente & 5 & $10 \%$ \\
Não entendeu seu problema & 5 & $10 \%$ \\
A pessoa causa pena & 5 & $10 \%$ \\
Está dominado pela bebida & 4 & $8 \%$ \\
Perdeu o sentido da vida & 3 & $6 \%$ \\
Não tem apoio familiar & 3 & $6 \%$ \\
A pessoa é fraca & 3 & $6 \%$ \\
Não tem fé & 2 & $4 \%$ \\
A pessoa é doente & 1 & $2 \%$ \\
Está sob influência maligna & 1 & $2 \%$ \\
Fez a escolha dele & 1 & $2 \%$ \\
Gosta de ser infeliz & 1 & $2 \%$ \\
É "burro" & 1 & $2 \%$ \\
\hline
\end{tabular}

E se não houver força de vontade? E se o "alcoólatra" não quiser tratamento? Os participantes foram solicitados a avaliar essa situação. A Tabela 4 traz os temas correspondentes. O número de citações de cada um dos temas é pequeno porque houve participantes que tiveram dificuldade de fazer essa avaliação (o que é, em si, um dado interessante) e alguns citaram muitos temas simultaneamente. Houve uma variedade muito grande de respostas, e as afirmações mais frequentes foram de que ele não tem amor próprio, não tem amor à vida, e de que ele é covarde, que não quer mudança.

Na situação em que o "alcoólatra" não quer se tratar, algo deve ser feito a ele? A Tabela 5, a seguir, mostra que quase todos os participantes responderam que sim. O tema "não (depois de tentar persuadir)" também é "sim", uma vez que algo já teria sido feito (a tentativa de persuasão). Sete participantes afirmaram que nada deve ser feito, pois "tem que partir dele", em continuida- 
de com o argumento de que a força de vontade é o requisito mais importante para o tratamento.

Tabela 5: Algo deve ser feito ao "alcoólatra" que não quer se tratar?

\begin{tabular}{l|c|c}
\hline Temas & $\mathbf{n}$ & $\mathbf{\%}$ \\
\hline Sim & 40 & $80 \%$ \\
Não, tem que partir dele & 7 & $14 \%$ \\
Não (depois de tentar persuadir) & 2 & $4 \%$ \\
Não, quem tem que mudar é a família & 1 & $2 \%$ \\
\hline
\end{tabular}

Um argumento dissonante, e de certa forma surpreendente, foi apresentado por uma participante: quem tem que mudar é a família. A participante afirmou que tem um pai "alcoólatra" e ele não aceita tratamento. Declarou que "ele não quer mudar, então, se ele não quer mudar, quem tem que mudar sou eu". Segundo essa ideia, a participante, sua família (e, por extensão, a sociedade) é que teriam que se adaptar à situação. Trata-se de um raciocínio raro, mas existente.

Tabela 6: O que deve ser feito ao "alcoólatra" que não quer se tratar?

\begin{tabular}{llc}
\hline Temas & n & \% \\
\hline Conversar para persuadi-lo a se tratar & 34 & $68 \%$ \\
Não adianta levar ao tratamento à força & 22 & $44 \%$ \\
Pode levar ao tratamento à força & 13 & $26 \%$ \\
\hline
\end{tabular}

Como se viu, a maioria dos participantes julgava que algo deveria ser feito a um "alcoólatra" que não quer se tratar. As alternativas encontradas foram três, como mostra a Tabela 6 (ver final do texto). A recomendação mais frequente foi que se converse com o "alcoólatra" para persuadi-lo a se tratar. Quem faria essa conversa seriam os familiares, que teriam que "se unir em torno da pessoa", amigos próximos ou profissionais de saúde. A conversa teria como condição que a pessoa estivesse sóbria no momento e assumiria um tom de "conscientização". O "alcoólatra" reconheceria os danos e perdas e se convenceria a se tratar, o que, no raciocínio dos participantes, correspondia necessariamente a parar de beber. Alguns participantes sugeriram que se mostrassem vídeos sobre o tema, ou mesmo outros "alcoólatras" em situação pre- 
cária nas ruas, como forma de convencimento. Para alguns, a conversa teria que contar com argumentos fortes, por exemplo: "um diálogo com palavras fortes, pra bater na consciência dela [da pessoa], pra ela analisar".

A recomendação de persuasão foi acompanhada muitas vezes da ideia de que não adianta levar ao tratamento à força. $O$ trecho que se segue exemplifica esse tema:

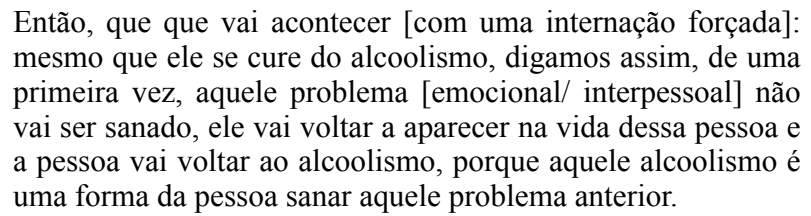

Por outro lado, cerca de um quarto dos participantes admitiram que a internação forçada seria uma alternativa válida. Na maioria das vezes, recomendaram a internação forçada somente em último caso, para estágios muito avançados do alcoolismo e/ou quando o risco de morte é muito alto. Em um dos casos, uma participante cujo irmão era alcoolista e estava sob seus cuidados, afirmou que o Estado deveria ajudá-la internando-o, porque a tarefa era "grande demais" para ela sozinha. Ela pediu a internação em um hospital "bem rígido".

\section{Discussão}

Esse conjunto de resultados pode ser interpretado com a Teoria das Representações Sociais, particularmente com os conceitos sobre os processos formativos das representações, objetivação e ancoragem, e com os conceitos sobre suas funções.

O discurso erudito sobre o alcoolismo e sua apropriação pelo senso comum diferem consideravelmente. A psiquiatria e a psicologia, que tomaram para si a tarefa de explicar o alcoolismo, tratam-no como síndrome multifacetada, cuja etiologia comporta vários fatores. Souza e Noto (2013) destacam que o saber médico contemporâneo entende a dependência como situação complexa, conjugando características psicológicas, biológicas e sociais. Não se considera o alcoolismo como condição inata. Sua gênese individual deve ser entendida como processo gradual e não como condição "tudo ou nada".

Dentre os conhecimentos científicos que permitem descrever o alcoolismo como doença, apenas alguns elementos foram retidos pelos participantes desta investigação. Por meio da objetivação, houve uma seleção ativa de imagens e ideias e uma articulação coerente desses elementos. Os dados coletados indicam que os participantes viam o alcoolismo como condição "tudo ou nada". 
O alcoolista foi objetivado como pessoa psicologicamente fraca. Isso é equivalente ao que foi encontrado por Ancel e Gaussot (1998) em não-alcoolistas franceses. Na análise desses autores, a ideia de fraqueza psicológica implicava também a percepção de que os alcoolistas eram "menos humanos".

A representação do alcoolismo como condição "tudo ou nada" implica na existência de um campo específico de significados e imagens. O alcoolista seria uma pessoa essencialmente diferente das outras. Isso é consistente com o que Ancel e Gaussot (1998) encontraram em meio aos participantes sobre as distinções entre "beber normalmente", "descer a ladeira alcoólica" e "submergir-se no álcool".

Alvarez (2001) mostrou que não-alcoolistas representam o alcoolismo como doença incurável e fatal e como condição que requer tratamento. Adicionalmente, a pesquisa relatada aqui mostrou que a origem do alcoolismo é principalmente atribuída a problemas emocionais ou à tentativa de escapar desses problemas. Em ambos os casos, a "fraqueza" psicológica do alcoolista apresenta-se como pressuposto. Nas representações estudadas, a "força de vontade" deve motivar o tratamento, que deve não só resolver o alcoolismo, mas também os problemas psicológicos que levaram a ele.

Nessas representações sociais, o alcoolista porta uma doença. Entretanto, não se trata de uma doença que vem de fora para dentro, como uma infecção por exemplo, mas sim de dentro para fora. Está presente a ideia de que há algo errado com o alcoolista, algo endógeno que o leva a sucumbir às bebidas alcoólicas. A doença é a perda do controle sobre o próprio comportamento, é a fraqueza da vontade. O alcoolista é visto como fraco e passivo, o que é semelhante ao que foi encontrado por Ancel e Gaussot (1998). A raiz da fraqueza não seria biológica, como sugere a tradição dos Alcoólicos Anônimos (CAMPOS, 2004), mas principalmente psicológica.

Os participantes desta pesquisa viam-se como não-alcoolistas. Seu eventual consumo de álcool era entendido por eles como "normal". O "beber bem" é associado a valores importantes como a responsabilidade e o autocontrole (ANCEL; GAUSSOT, 1998). As representações sociais do alcoolismo construídas pelos participantes ancoravam nessas percepções e ajudavam a construir ou reforçar aspectos de identidade. Ao falar sobre os alcoolistas, o grupo de não-alcoolistas pesquisado avaliou uma pessoa a quem dirigia atitude negativa.

Membros dos Alcoólicos Anônimos reconstroem o rótulo "alcoólatra" e passam a referir-se a si mesmos como "alcoólicos em recuperação", mantendo elementos positivos de identidade (CAMPOS, 2004). Alvarez (2004) estudou representações sociais do alcoolismo em dois grupos de alcoolistas: em tratamento e fora de tratamento. Nesses dois grupos, também identificou 
estratégias cognitivas para manutenção de autoavaliação positiva. Como prevê a Teoria das Representações Sociais, esse conjunto de estudos e a pesquisa aqui relatada sugerem que as representações do alcoolismo são construídas de forma diferente dependendo de sua ancoragem em determinados grupos e que essas representações não são construídas como fenômenos unicamente intraindividuais, mas sim como processos psicossociais que indicam relações dos sujeitos com o socius (DOISE, 2002).

É importante notar a ancoragem das representações sociais do alcoolismo em um conjunto de ideias e imagens de valor moral, sobre o "homem correto", a "mulher correta" (ALZUGUIR, 2014; ANCEL; GAUSSOT, 1998). Ressalta-se o conjunto semântico negativo associado à expressão "vício". A perda do controle sobre o comportamento implica perda dos limites morais. O alcoolista é percebido como oposto aos modelos hegemônicos de homem, ativo, trabalhador, chefe e provedor da família e aos modelos hegemônicos de mulher, responsável, terna, maternal, doméstica. As representações sociais do alcoolismo ancoram em significados bem enraizados de gênero (GAUSSOT, 2005). A categoria "doença" é um elemento importante da representação, mas não é suficiente para estabelecer seu sentido. É necessário ligá-la à perda do controle e à degradação moral/ psicológica.

A incorporação do elemento da visão médica (doença) e a manutenção da visão moral (vício, fraqueza) parecem constituir uma ambiguidade intrínseca das representações sociais do alcoolismo. Como previsto pela Teoria das Representações Sociais (MOSCOVICI, 1961/1978, 2007), diferentes racionalidades são mobilizadas para construir a realidade social, simbólica, objetiva-subjetiva do fenômeno.

Os resultados foram condizentes com aqueles encontrados por Ancel e Gaussot (1998). Os autores identificaram três formas relativamente autônomas, porém articuladas, de pensar o alcoolismo: a) a apropriação de raciocínios e conceitos médicos e psicológicos por parte do senso comum, incluindo explicações biológicas, psicológicas e ambientais para o fenômeno; b) a produção imaginária ligada ao colapso, à queda física e simbólica do alcoolista; e c) crenças associadas à degradação social e moral do indivíduo, implicando isolamento, ou seja, a "morte social" que antecipa a morte biológica. A visão moral é mais pregnante para o senso comum. A degradação moral do alcoolista é mais "concreta" e efetiva do ponto de vista cognitivo que a noção abstrata de doença.

É interessante destacar a centralidade dos fatores psicológicos na explicação que os participantes deram para o alcoolismo, localizando suas causas em problemas emocionais e/ou interpessoais e na busca por escapar a esses problemas, pressupondo "fraqueza psicológica". As representações sociais estudadas ancoravam em uma noção de "ser humano psicológico", tal como popularizada pelos saberes "psi". A pesquisa clássica sobre a representação social da psicanálise (MOSCOVICI, 1961/1978) mostrou que um dos elementos fortes dessa representação era o "recalcado" que 
poderia gerar "complexos". Na cultura "psicologizada", naturaliza-se a ideia de que "traumas geram problemas psicológicos".

A psicologização de indivíduos e grupos acompanhou a disseminação da psicologia como ciência nos séculos XIX e XX. Trata-se de característica comum em sociedades industrializadas, incluindo o Brasil. Uma das propriedades principais da psicologização é o reforço da individualização do sucesso e do fracasso. $\mathrm{O}$ individualismo pode ser visto como um dos mais hegemônicos elementos de representação de nosso tempo (FARR, 1991). Em sociedades industrializadas, a crença de que o indivíduo tem que superar obstáculos por meio de suas próprias habilidades e força de vontade individual é valorativa e prescritiva. Segundo essa crença, falhas ou problemas psicológicos têm causas que devem ser procuradas no indivíduo, em sua estrutura psicológica (FARR, 1991; ROSE, 2008).

Jodelet (1989/2005), no que diz respeito às relações com a doença mental, mostrou que são construídos vários tipos de separação, tanto no domínio simbólico quanto prático, com a função de proteger os "normais" da identificação com a loucura. O contato contínuo com a loucura implica ansiedades que geram regras de relação interpessoal e que geram representações sociais, de forma a que os sujeitos possam se proteger do medo do contágio.

Uma interpretação análoga pode ser feita em relação ao alcoolismo. $\mathrm{O}$ comportamento do alcoolista é percebido como fonte de isolamento social, autodestruição e morte. Representar o alcoolismo como doença e/ou vício de uma pessoa fraca é uma estratégia sociocognitiva para garantir a autoproteção individual e grupal contra a possibilidade de perda de controle, isolamento e morte.

Essas interpretações sobre funções de cunho intrapessoal e interpessoal combinam-se com as interpretações sobre funções macrossociais das representações do alcoolismo: reforçar crenças psicologizantes, individualizantes, estereótipos de homem correto, mulher correta, bom marido, boa esposa, bom trabalhador, etc., reforçando também as implicações desses fenômenos para a criação e manutenção os estilos de vida e modos de produção dominantes. Como destaca Doise (2002), as representações sociais se apresentam como fenômenos com implicações e com impactos simultaneamente intrapessoais, interpessoais e societais.

\section{Considerações finais}

As representações sociais do alcoolismo construídas pelos não-alcoolistas pesquisados produziam a realidade do fenômeno de forma a reforçar crenças e valores 
tradicionais. Ao mesmo tempo, é interessante destacar três ideias mencionadas pelos participantes que, apesar de não terem sido expressas com clareza conceitual, aproximam-se de visões inovadoras e do paradigma da redução de danos: 1) não adianta levar ao tratamento à força; 2) para tratar, é preciso criar um "vínculo de amizade" primeiro; e 3) "se o alcoólatra não quer parar de beber, quem tem que mudar sou eu". Essa última ideia implica considerar o alcoolista como sujeito de sua vida, mesmo que, para ele, a abstinência não seja possível ou desejável.

É interessante notar que nenhum dos participantes mencionou o CAPS -ad, apesar de se tratar de um serviço-chave para o tratamento de problemas relacionados com álcool e com outras drogas de acordo com a política de saúde brasileira (BRASIL, 2004) e apesar de haver um CAPS-ad no município onde os participantes foram entrevistados. Também não houve qualquer referência à expressão "redução de danos". O conjunto dos resultados indica que a lógica da redução de danos, apesar de ser uma diretriz oficial (BRASIL, 2004), está longe de ser um patrimônio compartilhado. Ao mesmo tempo, as ideias destacadas no parágrafo anterior talvez mostrem alguns caminhos já presentes no senso comum para a transformação das representações sobre os usuários de álcool e outras drogas.

Refletir sobre as representações sociais do alcoolismo construídas por não-alcoolistas pode contribuir para que familiares e profissionais envolvidos com o fenômeno questionem a estigmatização e a internalização do estigma sofridas pelo alcoolista, levando a melhores possibilidades de tratamento (SILVEIRA et al., 2013).

Práticas sociais inovadoras podem ser construídas por profissionais de saúde, por exemplo, em suas práticas clínicas e de atendimento psicossocial, de maneira a contribuir para transformar as representações sociais do alcoolismo e promover uma visão do fenômeno mais próxima ao que preconizam as diretrizes de promoção da saúde e de redução de danos. Ou seja, trata-se de promover a visão do alcoolista como agente ativo de sua vida e de seu tratamento, capaz de construir meios heterogêneos (questionando a abstinência como paradigma de solução única) para o cuidado de si e dos outros.

Essa visão pode ser exercida em diferentes níveis de atenção à saúde e especialmente na Atenção Primária à Saúde, caracterizada pela proximidade com os usuários e pela continuidade dos cuidados (KANNO; BELLODI; TESS, 2012). Pode permear a Triagem e Intervenção Breve para problemas com o álcool (SOUZA; NOTO, 2013), bem como os grupos de promoção de saúde. 


\section{Referências}

ALVAREZ, Armando Alonso. Representacion social del alcoholismo de personas alcohólicas. Psicologia em estudo, Maringá, PR, v. 9, n. 2, p. 151-162, 2004.

Representacion social del alcoholismo. Estudio comparativo de dos muestras (brasilera y cubana) de personas no alcoholicas. Revista cubana de psicología, [S.1.], v. 18, n. 2, p. 156$161,2001$.

ALZUGUIR, Fernanda Vecchi. A carreira moral da vergonha na visão de homens e mulheres "alcoólatras". Physis, Rio de Janeiro, v. 24, n. 1, p. 11-29, 2014.

ANCEL, Pascale; GAUSSOT, Ludovic. Alcool et alcoolisme. Pratiques et représentations. Paris: l'Harmattan, 1998.

ANDRADE, Tarcísio Matos de; FRIEDMAN, Samuel R. Princípios e práticas de redução de danos: interfaces e extensão a outros campos da intervenção e do saber. In: SILVEIRA, Dartiu Xavier da; MOREIRA, Fernanda Gonçalves. (Orgs.). Panorama atual de drogas e dependências. São Paulo: Atheneu, 2006, p. 395-400.

BARDIN, Laurence. Análise de conteúdo. Lisboa: Edições 70, 1977.

BRASIL. (Ministério da Saúde. Secretaria Executiva. Coordenação Nacional de DST/Aids.) A Politica do Ministério da Saúde para atenção integral a usuários de álcool e outras drogas / Ministério da Saúde, Secretaria Executiva, Coordenação Nacional de DST e Aids. - Brasília: Ministério da Saúde, 2004.

CAMPOS, Edemilson Antunes de. As representações sobre o alcoolismo em uma associação de ex-bebedores: os Alcoólicos Anônimos. Cadernos de Saúde Pública, Rio de Janeiro, v. 20, n. 5 , p. $1379-1387,2004$.

DOISE, Willem. Da psicologia social à psicologia societal. Psicologia teoria e pesquisa, Brasília, DF, v. 18, n. 1, p. 27-35, 2002.

FARR, Robert. Individualism as a collective representation. In: AEBISCHER, V.; DECONCHY, J. P.; LIPIANSKY, R. (Orgs.). Ideologies et representations sociales. Fribourg: Delval, 1991, p. 129-143.

GAUSSOT, Ludovic. Le déni, la honte et la "différence des sexes". In : DUPONT, Liliane; DASSONVILLE, Anne; CRESSON, Geneviève. (Orgs.). Alcool, grossesse et santé des femmes. Lille: ANPAA 59, 2005, p. 90-97.

HALPERN, Elizabeth Espindola; LEITE, Ligia Costa. "Pinguço", "cachaça”, "bebum": a sociodinâmica da estigmatização no trabalho naval. Revista de Ciências Humanas, Florianópolis, v. 48, n. 2, p. 329-351, 2014.

JODELET, Denise. Loucuras e representações sociais. Petrópolis: Vozes, 1989/2005.

KANNO, Natália de Paula; BELLODI, Patrícia Lacerda; TESS, Beatriz Helena. Profissionais da Estratégia Saúde da Família diante de demandas médico-sociais: dificuldades e estratégias de enfrentamento. Saúde e sociedade, São Paulo, v. 21, n. 4, p. 884-894, 2012. 
LARANJEIRA, Ronaldo et al. Resultados parciais do II Levantamento Nacional de Álcool e Drogas. Consumo de Álcool no Brasil - Tendências entre 2006-2012. São Paulo: INPAD. Disponível em: http://inpad.org.br/lenad/resultados/alcool/resultados-preliminares/ Acesso em: 02 de dezembro de 2014.

MOSCOVICI, Serge. Representações sociais. Investigações em psicologia social. Petrópolis: Vozes, 2007. . A representação social da psicanálise. Rio de Janeiro: Zahar, 1961/1978.

NAHOUM-GRAPPE, Véronique. Vertige de l'ivresse. Alcool et lien social. Paris: Descartes \& Cie, 2010.

POPE, Catherine; ZIEBLAND, Sue; MAYS, Nicholas. Analisando dados qualitativos. In: POPE, Catherine; MAYS, Nicholas. (Orgs.). Pesquisa qualitativa na atenção à saúde. 2 ed. Porto Alegre: Artmed, 2005, p. 87-99.

ROSE, Nikolas. Psicologia como uma ciência social. Psicologia e sociedade, Belo Horizonte, v. 20, n. 2, p. 155-164, 2008.

SANTOS, Walberto Silva et al. Medindo consumo de álcool: análise fatorial confirmatória do Alcohol Use Disorder Identification Test (AUDIT). Psico-USF, Itatiba, SP, v. 18, n. 1, p. 121130, 2013.

SANTOS, Vilmar Ezequiel; SOARES, Cássia Baldini; CAMPOS, Célia Maria Sivalli. A produção científica internacional sobre redução de danos: uma análise comparativa entre MEDLINE e LILACS. SMAD - Revista eletrônica saúde mental álcool e drogas, [S.1.], v. 8, n. 1, 2012, p. 41-47.

SILVEIRA, Pollyanna Santos et al. Estigma e suas consequências para usuários de drogas. In: RONZANI, Telmo Mota. (Org.), Ações integradas sobre drogas: prevenção, abordagens e políticas públicas. Juiz de Fora: Editora da UFJF, 2013, p. 251-274.

SOURNIA, Jean-Charles. Histoire de l'alcoolisme. Paris: Flammarion, 1986.

SOUZA, Isabel Cristina Weiss.; NOTO, Ana Regina. Abordagens para usuários de álcool. In: RONZANI, Telmo Mota. (Org.), Ações integradas sobre drogas: prevenção, abordagens e politicas públicas. Juiz de Fora: Editora da UFJF, 2013, p. 105-122.

TRINDADE, Zeidi Araújo; SANTOS, Maria de Fátima de Souza; ALMEIDA, Angela Maria Oliveira. Ancoragem: notas sobre consensos e dissensos. In: ALMEIDA, Angela Maria Oliveira; SANTOS, Maria de Fátima de Souza; TRINDADE, Zeidi Araújo. (Orgs.). Teoria das Representações Sociais: 50 anos. Brasília: Technopolitik, 2011, p. 101-122.

Submissão em: 17/12/2014

Revisão em: 01/02/2015

Aceite em: 31/03/2015

Luiz Gustavo Silva Souza é doutor em Psicologia pela Universidade Federal do Espírito Santo. Professor do Departamento de Psicologia da Universidade Federal 
Fluminense, Campos dos Goytacazes. Professor colaborador do Programa de PósGraduação em Psicologia da Universidade Federal do Espírito Santo. Endereço para correspondência: Rua José do Patrocínio, n. 71, Centro, Campos dos Goytacazes, RJ, CEP 28030-130. E-mail:1 1uizsouza@hotmail.com.

Maria Cristina Smith Menandro é doutora em Psicologia, professora do Programa de Pós-Graduação em Psicologia da Universidade Federal do Espírito Santo. E-mail: crismenandro@uol.com.br

Zeidi Araújo Trindade é doutora em Psicologia, professora do Programa de Pós-Graduação em Psicologia da Universidade Federal do Espírito Santo. E-mail: zeidi@uol.com.br 